ANÁLISIS DE, LA

PARTICIPACION DEL

LECTOAUTOR EN LA

CONSTRUCCION DEL

VIDEOJUEGO

\title{
Mario Rajas
}




\section{Análisis de la participación del lectoautor en la construcción del videojuego. \\ (Mario Rajas)}

\section{Resumen}

Uno de los aspectos susceptibles de análisis más fascinantes que podemos encontrar en los medios de entretenimiento contemporáneos es, sin duda, la progresiva importancia que la intervención activa por parte del receptor ha ido adquiriendo en la propia construcción de contenidos y discursos de esas formas culturales de ocio.

El videojuego, como manifestación más avanzada de esa participación lectora en la creación de los textos, resulta un campo de investigación excepcional para comprender hasta que punto la interactividad y la autoría abierta y compartida han devenido los rasgos más sobresalientes a la hora de realizar un producto de entretenimiento audiovisual.

En este artículo repasaremos los distintos ámbitos donde esta participación por parte del jugador resulta más evidente, no circunscrita meramente al acto de jugar, sino como aportación relevante a la creación del propio texto, y señalaremos las vías potenciales que comienzan ya hoy a vislumbrarse en un futuro no tan lejano.

\section{Introducción.}

El entretenimiento audiovisual ha experimentado, en un corto espacio de tiempo, una auténtica revolución en sus estructuras industriales y creativas. Hace menos de treinta años que el videojuego irrumpió tímidamente como nueva forma cultural de ocio, todavía muy desvinculado y distanciado, en cuanto a funciones sociales, intereses comunicativos o éxito de mercado, respecto a otros medios largamente asentados como el cine o la televisión. En la actualidad el discurso electrónico de los videojuegos genera un volumen de negocio superior a la industria cinematográfica, en determinadas capas sociales (jóvenes, sobre todo), tiene mayor aceptación, consumo y fidelidad que la hasta hace poco hegemónica y aparentemente inalcanzable televisión, $\mathrm{y}$, en cuanto a los aspectos creativos, que son los que vamos a abordar con detenimiento en este artículo, las mayores aportaciones y transformaciones, en el ámbito de la tecnología, la técnica, la poética, la narrativa, la retórica, la estética y, sobre todo, la pragmática audiovisual, han provenido del campo del videojuego. 
Con cierto retraso, y sin vencer todavía por completo las reticencias que siempre acompañan a la aparición de nuevos fenómenos, empieza a comprenderse la relevancia que está alcanzando el videojuego y comienzan a producirse investigaciones teóricas pluridisciplinares que intentan analizar esta nueva forma de ocio desde las más variadas perspectivas. Dentro de estos acercamientos, el estudio de la creatividad bidireccional en los videojuegos ocupa un lugar visiblemente destacado.

Al tratarse de una manifestación cultural en continua mutación y reinvención de sí misma, los aspectos constructivos de la misma, es decir, cómo se crean los contenidos y discursos que vertebran los textos de ocio electrónico, son el fundamento mismo de su existencia y desarrollo. Mucho más acusadamente que en el cómic o el cine, donde por diversos motivos es más justificable un estancamiento, los hallazgos, las mejoras, las invenciones, los saltos sin red hacia el futuro, son consustanciales al propio videojuego, que demanda permanentemente ir superando barreras en todos los órdenes formales para su propia supervivencia como producto y objeto de creación fundamentalmente tecnológico. No hay más que tomar un juego deportivo, de fútbol, por ejemplo, las sagas de FIFA (desde 1994) y Pro Evolution Soccer (que ya alcanza la cuarta entrega) y constatar que, año tras año, se van sucediendo versiones del mismo que necesitan aportar nuevas funciones, mejores gráficos, más apariencia de simulación de la realidad o nuevos alicientes comunicativos, como son las licencias de equipos o jugadores profesionales, para poder llamar la atención de los posibles consumidores, lo que supone, a su vez, ir subiendo el nivel global de los videojuegos, como creaciones siempre necesitadas de superar drásticamente, en todas las áreas, lo efímeramente establecido.

El imparable desarrollo tanto de las plataformas (ordenadores personales, consolas, máquinas recreativas) como de los propios videojuegos en sí, convierten la creatividad en el eje fundamental del ocio electrónico sobre el que pivota, cada vez de forma más evidente, al alejarse paulatinamente de la etapa inicial, inherente a todo nuevo medio, de invención y establecimiento del dispositivo, la emisión y recepción de esta forma de entretenimiento cultural.

El aspecto más sobresaliente, aparte de las múltiples facetas comunicativas y artísticas que podemos descubrir en los propios textos, es que el proceso creativo, al contrario de lo que sucede en otros medios, no resultan patrimonio exclusivo del constructor de los enunciados, sino que en el caso del ocio electrónico, el jugador, el receptor, al participar activamente en distintos aspectos de esa construcción, detenta una 
serie de funciones creativas perfectamente definibles, sin las cuales, y cada vez con mayor intensidad, el videojuego no tiene verdadera razón de ser.

Analizaremos a continuación esas dos formas de creatividad, en el orden constructivo en el que se producen: primero, la enunciación discursiva de un producto aparentemente acabado, el videojuego y, luego, la participación del jugador dentro de la propia configuración de ese proceso comunicativo y artístico.

\section{La participación del jugador en la construcción de un videojuego.}

"En definitiva, los autores al finalizar sus trabajo consideraron que el videojuego es esencialmente una actividad de carácter social y pocas veces es vista como un logro o una meta en sí misma"

(Estallo, 1995, 55)

La estrecha relación que el desarrollo del ocio electrónico mantiene con los avances tecnológicos, ya sea en la configuración del consumo del mismo en torno a una serie de espacios muy definidos (el domicilio particular, el salón recreativo, los locales de partidas en red), ya sea en la serie de plataformas necesarias para jugar, hace que debamos referirnos a estos aspectos junto con las vinculaciones concretas que las divergentes sustancias expresivas y su tratamiento en la configuración poética, narrativa, retórica o pragmática de un videojuego tienen con el proceso creativo del mismo.

\subsection{Arquitecturas de juego. EI espacio y la plataforma}

La construcción textual de los videojuegos depende sobremanera del lugar de disfrute del mismo y, estrechamente ligado a él, del soporte hardware o plataforma para la que está diseñada dicha construcción textual.

El espacio de entretenimiento ha sido, además de su lógica base como lugar de consumo o intercambio comercial, un área donde desarrollar la inventiva por parte de los profesionales del sector. No hay más que aproximarse a un salón recreativo y constatar la variedad de dispositivos que se ofrecen: desde las tradicionales máquinas tipo consola a complejos equipos que simulan cabinas de avión, tablas de snowboard o ametralladoras a modo de interfaz. Debido a la competencia que progresivamente 
supuso la entrada del ocio electrónico en los hogares, por medio de las consolas enchufadas al televisor y los ordenadores personales, los salones recreativos han ido especializándose, para atraer y retener jugadores, en toda esta serie de elaboradas arquitecturas, con la intención, paulatinamente desarrollada, de ir acercándose a una integración total del jugador en el espacio de juego, a la inmersión absoluta en la realidad virtual.

"La realidad virtual es una tecnología hipermedia que utiliza sustancias expresivas cineinfográficas tridimensionales y sonoras para crear mundos posibles por los que el lectoautor puede moverse libremente. Esta es la cualidad definitoria de la realidad virtual, la posibilidad de movimientos libres por los espacios virtuales como si fueran reales"

(Moreno, 2002, $80-81$ )

Aunque queda mucho camino por recorrer en este sentido, los límites entre lo natural y lo virtual resultan cada vez más confusos $\mathrm{y}$, sin duda, tenderán a ir difuminándose aún más con el paso del tiempo. Lo que debemos destacar aquí es que, como veremos con mayor detenimiento, la principal función de estas arquitecturas sorprendentes (por ejemplo, motos con dispositivos sensoriales que al colisionar el usuario con una valla le producen una fuerte sacudida) es provocar una participación cada vez más activa y envolvente por parte del jugador, que le vaya alejando progresivamente de la sensación convencional de encontrarse frente a una máquina y le vaya sumergiendo en ese mundo posible creado ex profeso para él.

En la misma línea puede situarse la reciente aparición, y éxito, de un nuevo espacio de recreo: los locales, materiales o virtuales, de partidas en red.

Si el hogar comenzó como un espacio de juego claramente individual (los primeros ordenadores que disfrutaron de una recepción masiva por parte de los consumidores, como el Spectrum o el Amstrad, estaban fundamentalmente enfocados para un solo jugador), o como mucho, constreñido a un número limitado de jugadores (normalmente, no más de cuatro, en las consolas), lo que era considerado (y vilipendiado por ello) un ocio puramente unipersonal, se ha convertido en una de la actividades colectivas con mayor implantación dentro de las distintas opciones de entretenimiento en grupo que nuestra cultura ofrece. Su rápida implantación puede 
observarse fácilmente en la cantidad de juegos que incluyen el modo multijugador como principal opción de juego a la hora de atraer al posible receptor. De hecho, los desarrollos narrativos lineales basados en la confrontación de un único jugador humano contra la máquina, están perdiendo peso en los textos en detrimento de construcciones abiertas ("sin hacer") fundamentadas en guiones improvisados e irrepetibles que se actualizan en cada nueva partida multijugador.

Ya sea en locales comerciales expresamente habilitados para el desarrollo de esta actividad, ya sea mediante la posibilidad de crear redes particulares entre amigos conectando varios equipos, o ya sea en el espacio aislado de los distintos hogares que pueden conectarse a través de Internet a macropartidas on-line o ligas donde participa un gran número de usuarios, el ocio electrónico está desplazando marcadamente su creatividad a este ámbito colectivo de acción, como veremos a la hora de tratar las construcciones textuales que están convirtiéndose en hegemónicas en la actualidad.

Por otro lado, no podemos dejar de abordar la profunda y vertiginosa transformación que ha sufrido la base tecnológica que sustenta los videojuegos. Desde las primitivas plataformas experimentales de finales de los setenta, las máquinas de ocho bits que coparon el mercado doméstico en la siguiente década (en ordenadores, los mencionados Spectrum y Amstrad, además del MSX y el Commodore 64; en consolas, la Nintendo Nes o la Sega Master System), la posterior implantación, a comienzos de los noventa, de la generación de consolas de 16 bits, con la SuperNintendo y la Sega Megadrive como principales y prolongados representantes, así como el lento establecimiento del PC como multiplataforma hegemónica no exclusivamente diseñada para el ocio, desplazando, a continuación, a estas máquinas, la Sony Playstation y Nintendo 64, hasta las actuales Sony Playstation 2, Microsoft Xbox y Nintendo Gamecube, plataformas todas ellas de 64 bits con el DVD como soporte principal, así como la definitiva institución del PC como centro neurálgico del ocio electrónico, los avances tecnológicos, posibilitando todo tipo de invenciones expresivas, no han dejado de sucederse a una velocidad inaudita en los medios de masas. Esta permanente evolución trae consigo la necesidad de un trabajo de equipos humanos en constante proceso de aprendizaje y superación, lo que provoca que la industria del videojuego sea una de las más competitivas, comercial y creativamente hablando, de las que actualmente componen el panorama audiovisual. El surgimiento de nuevas plataformas, periféricos o adelantos técnicos en cuanto a las capacidades gráficas y sonoras de los equipos, es el motor que tira de la participación del jugador, no como mero invitado ocasional, sino 
como auténtico profesional que necesita conocer esos nuevos soportes para completar satisfactoriamente la actividad. Es decir, el jugador requiere de unos conocimientos especializados, por ejemplo, para crear una partida en red con varios puestos o introducir una serie de mejoras, como una nueva tarjeta de video, en su propio equipo, que le convierten a él mismo en un creador de su propia plataforma de disfrute y en un potencial investigador de nuevas formas tecnológicas de ocio. Basta apuntar al respecto la gran cantidad de trabajos diseminados por Internet realizados por usuarios particulares que, más allá del hecho de jugar, comparten los más variados hallazgos y propuestas respecto al ámbito general de las plataformas y los videojuegos en sí. Desde cómo conseguir sacar el mayor rendimiento posible a un equipo, hasta como programar versiones propias de los juegos, pasando por invenciones de particulares sobre hardware que en no pocas ocasiones acaban integradas en la industria profesional, la frontera entre inventor - usuario no está nunca tajantemente delimitada, y, por el contrario, tiende a estrecharse cada vez más, salvando las distancias económicas, el marco de actuación entre los que idean tecnología y los que disfrutan de esas creaciones.

\subsection{La construcción compartida de los textos.}

"Una forma de describir un juego de ordenador es "una serie de decisiones interesantes". Si los juegos de ordenador nos gustan es porque nos permiten interactuar con la historia, en vez de limitarnos a verla y percibirla de forma pasiva. Por tanto, al crear un juego, procura que el jugador tenga una gran capacidad de reacción"

(Saltzman, 2001, 43)

Sin duda, cuando hablamos de la creación de un videojuego, el propio objeto textual es la principal referencia a la que debemos remitirnos.

Como hemos apuntado anteriormente, no ha estallado todavía, aunque empiezan a producirse algunos trabajos de interés al respecto, un estudio teórico sistematizado como el que ha sobrevenido a todas las manifestaciones culturales producidas a lo largo de la historia. Desde la narrativa, la poética, la retórica, la pragmática o cualquier otro campo afín a la creación y análisis textual, el videojuego resulta un campo inexplorado de investigación, pleno de recursos que entender y explicar. La acelerada práctica textual que se realiza en el ámbito de los videojuegos, va muy por delante de las 
interpretaciones teóricas de los mismos fenómenos, y, exceptuando el propio estudio que los profesionales llevan a cabo al proyectar sus obras, no se ha generado la cantidad de acercamientos académicos que sería lógico encontrar en una manifestación de ocio tan extendida. Comienzan a abrir las primeras escuelas para técnicos, a expedirse, tímidamente, las primeras titulaciones oficiales, pero en general el videojuego como obra de creación todavía anda muy desvinculado de de la docencia audiovisual y de su espacio más adecuado de investigación, la universidad.

Esto repercute, así mismo, en la práctica, aunque se esté corrigiendo a pasos agigantados esta tendencia (existen ya guionistas o realizadores reconocidos por su trabajo al frente de videojuegos, como Peter Molineux, Ron Gilbert o Hideo Kojima), todavía perdura muy ligada al trabajo de equipos técnicos determinados (área de grafismo, de diseño de estructuras, de programación...) y no al de comunicadores propiamente dichos, que generen, a su vez, un estudio teórico paralelo. Nos encontramos, salvando las distancias, en esa época que vivió el cine ("de los pioneros") en el que todo aprendizaje de la profesión se circunscribía al desempeño de la misma.

Las áreas a tratar, en cuanto al análisis textual, resultan muy heterogéneas y se encuentran todavía dispersas bajo determinadas perspectivas (la tecnológica domina, la narrativa comienza a abrirse hueco) sin integrarse en una disciplina propia que de conveniente acomodo a todas esas divergentes materias.

Por un lado, la creatividad esta muy asociada al tratamiento de las sustancias expresivas que forman materialmente un videojuego. El aspecto visual del mismo, esto es, su imagen gráfica, ha sido el ámbito mejor estudiado de este apartado. La progresiva búsqueda de establecimiento de formulas gráficas tridimensionales y la correspondiente superación de los mundos construidos en 2-D, así como la extraordinaria diversidad y calidad de disposiciones gráficas, al ser el videojuego completamente independiente de materiales apriorísticos registrados de la realidad (como ocurre con el cine o la fotografía), han hecho del aspecto visual de los juegos la manifestación creativa más importante de la actualidad. La integración de imagen fija y secuencial, infografía y texto, permiten múltiples combinaciones a cual más interesante. El trabajo conjunto de ilustradores, grafistas, programadores, etc. se aprecia en libros y exposiciones dedicadas especialmente a destacar este atrayente universo de imagen gráfica que el videojuego ha inventado.

A su vez, aspectos, que no gozaban de tanta relevancia, como el sonido, han visto potenciadas sus características expresivas hasta extremos insospechados. Para la 
creación de las bandas sonoras de los juegos se ha recurrido a músicos profesionales (grabaciones preexistentes $\mathrm{u}$ originales de grupos de rock o hip hop, orquestas sinfónicas, compositores de reconocido prestigio, etc...) a la hora de diseñar y elaborar el audio de los juegos, produciéndose en la actualidad el fenómeno de que algunos de estos trabajos son editados en formatos independientes con el ánimo de promover aparte su consumo en el mercado discográfico.

Las voces, diálogos y sonidos ambiente también han ido cobrando importancia en el entramado discursivo, amparados por las posibilidades tecnológicas y la progresiva complejidad de las estructuras narrativas de los productos. Un videojuego sin la conveniente traducción idiomática tiene muchas menos opciones de ser bien recibido por el jugador habitual, que ha establecido la comunicación (con la máquina y con otros usuarios) como la principal tarea que debe acometer todo juego que se imponga unos niveles básicos de calidad.

Estas sustancias expresivas audiovisuales han sido, a su vez, convenientemente tratadas en el proceso de realización de las obras en sí. Resulta significativo comprobar como los esquemas que suelen aplicarse a los relatos secuenciales fílmicos, como la teoría de géneros, el punto de vista o la angulación, se han traspasado al estudio de los videojuegos con absoluta fidelidad, produciéndose un desplazamiento, eso sí, del texto fílmico (lo principal a la hora de definir un thriller o señalar un plano picado) al texto videojuego pero entendido desde la perspectiva del jugador. Por ejemplo, los géneros en el videojuego vienen delimitados por el tipo de acción que se espera del usuario, como la habilidad o la estrategia, y así tenemos los arcades, los simuladores o las aventuras gráficas entre otros géneros; el punto de vista se define por la integración del jugador con la figura que lo representa, y así tenemos la vista en primera persona (vemos el mismo espacio-tiempo que el personaje que controlamos), que en el cine se denominaba subjetiva, y la vista en tercera persona (vemos al personaje que controlamos y el resto del espacio-tiempo), que en el cine denominábamos semisubjetiva (como en los juegos $3 \mathrm{D}$ en tercera persona) $\mathrm{u}$ objetiva (como en los juegos $2 \mathrm{D}$ de scroll vertical $\mathrm{u}$ horizontal); y la angulación, o vista del jugador respecto al espacio - tiempo de juego, que puede ser cenital, isométrica o lateral entre otras variantes. Lo que queremos destacar, es que en todos estos casos la referencia principal es el lugar del jugador respecto al texto. El espacio comunicativo desde el que aborda su relación con el videojuego es la piedra angular de toda la creación del ocio electrónico. 
Está por realizar, como hemos advertido, un estudio pormenorizado que verse sobre todos estos aspectos constructivos en la producción de un videojuego. Si compilar una gramática, como ocurre con el audiovisual en conjunto, no resulta posible, sí es necesario, como sucede así mismo en otros medios, que se investiguen los conformantes de la realización de un videojuego. Qué los iguala a los tratamientos audiovisuales (las sustancias expresivas como la imagen secuencial, por ejemplo) y qué lo convierten en una manifestación diferente (los motores gráficos, la estructura narrativa abierta...). La propia práctica profesional está demandando una indagación teórica que haga aún más provechosa la permanente aportación creativa que se produce en el mundo del videojuego.

Además de las sustancias expresivas convenientemente tratadas que conforman el discurso del videojuego, encontramos, completando el entramado narrativo del mismo, los contenidos (espacio, tiempo, acciones y personajes) que ofrecen en la actualidad el campo más proclive a la intervención activa del jugador.

Efectivamente, la participación y transformación de una base textual común en algo propio e irrepetible por parte del usuario se produce a nivel de los contenidos más que a nivel del discurso, todavía reservado en mayor medida al ámbito de actuación del creador. Las sagas de juegos que están teniendo mayor aceptación por parte del público (como los simuladores de realidad, tipo Sims o las aventuras on-line, tipo Line Age) tienen en común una estructura abierta (no lineal o constreñida a un desarrollo prefijado de niveles, fases o etapas secuenciales a cubrir) y una gran participación requerida al jugador para la creación física, psicológica y social de su personaje y las acciones que debe realizar para llevar a buen puerto la aventura. Si todavía siguen dominando las opciones previamente dirigidas por los autores (por ejemplo, a la hora de elegir los atributos físicos de los personajes se selecciona dentro de un menú con distintas variables), estas constricciones apriorísticas tienden a ir desapareciendo, siendo sustituidas por intervenciones propias, sin limitaciones previas, por parte del jugador. Así, en algunos juegos como Los Sims 2, se permite introducir los propios rasgos físicos del jugador, por medio del escaneado de una foto y su posterior conversión a personaje, o en juegos en primera persona tipo Quake o Half Life, sustituir con un avatar personal los modelos de personajes que propone el juego.

El jugador, además, genera su propia secuencia de juego, fabricando su tiempo, sus preferencias teleológicas y sus recorridos cronológicos en la consecución de una meta 
cada vez menos dependiente de una trama lineal establecida que de las propias intenciones del usuario.

Pero aún es más, al igual que ocurría con las aportaciones tecnológicas que comentábamos más arriba, el jugador se ha apropiado de una parte importante de la creación de videojuegos, como es el diseño y ejecución de mapas o fases del mismo. Casi todos los shoot 'em up en primera persona tienen cientos de localizaciones creadas (siguiendo el motor respectivo de cada juego) por aficionados anónimos que lo suben a la red para el disfrute gratuito de otros jugadores. Nuevas misiones, mods, objetos inventados, ampliaciones de todos los constituyentes del juego...las desarrolladoras de ocio electrónico se han dado cuenta que la prodigiosa aportación desinteresada de los usuarios es uno de las pilares más firmes para que el juego siga teniendo vida creativa y comercial, hasta convertirlo, por medio de estas reactualizaciones, en un producto no perecedero. A su vez, los usuarios han expandido su tiempo de ocio, más allá de la narración concreta del videojuego y se han inmiscuido en la elaboración del mismo, por medio de esas intromisiones que hemos apuntado, dejando de ser meros jugadores para convertirse en lecto autores de los propios textos.

Es cierto que siempre tendrá que haber un comunicador que comience la relación con el jugador, que cree la base sobre la que este pueda introducir modificaciones, pero estos ejemplos que hemos propuesto señalan, y sobre todo, abren, una nueva forma de concebir dicha relación, en la que ya no podremos diferenciar tan tajantemente las funciones de emisor y receptor y, sobre todo, ya no podremos atribuir, a este segundo, un papel meramente pasivo o poco relevante en la toma de decisiones que afectan al desarrollo constructivo de dicha relación.

\section{Bibliografía:}

DEMARIA, RUSEL y WILSON, JOHNNY L, High Score!: La historia ilustrada de los videojuegos, McGraw-Hill / Interamericana de España, 2002

ESTALLO, JUAN ALBERTO, Los videojuegos. Juicios y prejuicios, Planeta, 1995

LEVIS, DIEGO, Los videojuegos, un fenómeno de masas, Paidós, 1997

MORENO, ISIDRO, Musas y nuevas tecnologías, el relato hipermedia, Paidós, 2002

SALTZMAN, MARC (Compilador), Cómo diseñar videojuegos, los secretos de los expertos, Norma, 2001

VV.AA., La pequeña gran historia de los videojuegos, Revista Micromanía, 2000 